\title{
Application of Tahmid Spiritual Therapy to Reduce the Anxiety Level of Pre Sectio Caesarea Patients in Islamic Hospital Sultan Hadlirin Jepara
}

\author{
$1^{\text {st }}$ Sri Karyati \\ Department of Nursing \\ University Muhammadiyah of Kudus \\ Kudus, Indonesia \\ srikaryati@umkudus.ac.id
}

\author{
$2^{\text {nd }}$ Muhammad Hanafi \\ Department of Nursing \\ University Muhammadiyah of Kudus \\ Kudus, Indonesia
}

\author{
$3^{\text {rd }}$ Taufiq \\ Department of Nursing \\ University Muhammadiyah of Kudus \\ Kudus, Indonesia
}

\begin{abstract}
Surgical programs often cause fear and anxiety to patients, including the SC program. Anxiety is a psychological response that can cause physiological problems that disrupt the operation process. Nursing care can use a spiritual approach to control patient anxiety. Tahmid is one of the readings that can calm the heart. The aims of study was to determine the effect of tahmid spiritual therapy to reduce the anxiety level of of patients pre $\mathrm{SC}$. The population was pre SC patients, with 22 respondents divided into intervention and control groups. Data collection using the Zung Self-rating Anxiety Scale instrument. There was a significant decrease the anxiety level of the intervention group (p 0.037) but there was no in the control group (p 0.774). There was no significant difference in anxiety levels between the intervention group and the control group ( $\mathbf{p}=$ 0.183). Nurses must not forget the psychological and spiritual approach in treating patients.
\end{abstract}

Keywords-Tahmid Spiritual, Application, Therapy, Anxiety Level

\section{INTRODUCTION}

Surgery always causes anxiety for patients, including sectiocesarea (SC). Anxiety arises because of surgical procedures, fear of facing post-operative inability, and fear of death. SC is a birthing operation that is performed due to several birth problems, both because of the narrow birth canal, the baby being too large, lack of strength, and because of an abnormal fetal condition. Maternal anxiety in SC surgery becomes more complex. Anxiety increases because the mother is not only worried about her own condition but is more concerned about her baby's condition and safety [1][2].

Anxiety before surgery can affect the body's hemostatics in the form of increased use of oxygen so that the body changes it by increasing blood pressure, increasing the frequency of the pulse, and increasing the rate of breathing. This condition can ultimately reduce the blood supply to the fetus which can cause fetal distress and can interfere with surgery. For this reason, efforts need to be made to reduce the level of maternal anxiety [1][3].
Efforts to reduce maternal anxiety can be done nonpharmacologically by managing maternal stress. The basis of stress management is to help mothers to be able to recognize, explore and control stress. Spiritual approach is one effective way that can be done. The combination of relaxation techniques and the strength of good belief are the success factors in relaxation. The element of belief that will be used in the intervention is the element of religious belief. The element of belief included is the reading of words or sentences that are in accordance with the respective religious beliefs accompanied by an attitude of surrender. One of them is thankful for what God has given by saying Tahmid [2][4].

Tahmid is one of the dhikr or remembrance to remember God, praising God for all the gifts that have been given to us. Tahmid is the saying "Alhamdulillahirobbil" alamin "which means all praise is to Allah, Lord of the worlds. This, if spoken sincerely, is believed to provide peace of mind and can increase human motivation. The application of tahmid spiritual therapy is done by focusing the mind by breathing after the mind is relaxed, while breathing on respondent is asked to say tahmid in the heart [5].

The purpose of this study was to analyze the reduction in pre-SC maternal anxiety between groups given human therapy with groups that only did deep breathing relaxation.

\section{METHODS}

This study was a quasi-experimental, with pre-test and post-test nonequivalent control. The population is mothers who will undergo SC operations at RSI Sultan HadlirinJepara by taking 22 samples divided into 2 groups of 11 people each. The intervention group will be treated Tahmid spiritual therapy while the control group will do deep breathing relaxation therapy. The instrument for respondent's anxiety level data uses the Zung Anxiety Scale Self-Rating Scale where the value per item is in the range 1-4. The total range of scores from 20 to 80 will be categorized on a score of 20-44: overcoming mild, Score 
45-59: medium of challenge, Score of 60-74: weight of challenge, and Score of 75-80: risk of excavation

Before therapy, respondent adjusts her position as comfortable as possible, then completes the therapeutic steps. Relaxation Therapy Deep breathing is done by taking a breath to pass the examination of about 3 to 4 beats, maintained in about 1 to 2 beats then exhaled slowly through the mouth about 4 beats. In the control group, this therapy was carried out for 10 minutes.

Tahmid spiritual therapy begins with relaxation breathing therapy in 3 minutes. Followed by core therapy hamdalah, by continuing to breathe deeply, at the time of inspiration, respondents examine the intelligence of Tahmid with their hearts and support their gratitude for God's goodness. This is done for 7 minutes.

Data about changes in the level of anxiety of respondents between the deep breath therapy group and the Tahmid spiritual therapy group were analyzed using the Mann Witney formula.

\section{RESULT AND DISCUSSION}

Distribution of the characteristics of respondents between the intervention group and the control group is equivalent. The majority are in the age range of 25-30 years, high school education, and work as employees. In both groups there were no respondents with fetal distress.

Data distribution of anxiety levels before and after treatment in the intervention group and the control group can be seen in table I.

TABLE I. DISTRIBUTION OF ANXIETY LEVELS BEFORE AND AFTER TREATMENT IN THE INTERVENTION GROUP AND THE CONTROL GROUP

\begin{tabular}{|l|l|l|l|l|l|l|l|l|}
\hline \multirow{3}{*}{ Anxiety levels } & \multicolumn{3}{|l|}{ Intervention group } & \multicolumn{3}{l|}{ Control group } \\
\cline { 2 - 9 } & \multicolumn{2}{|l|}{ Pre } & \multicolumn{2}{l|}{ Post } & \multicolumn{2}{l|}{ Pre } & \multicolumn{2}{l|}{ Post } \\
\cline { 2 - 9 } & f & $\%$ & f & $\%$ & f & $\%$ & f & $\%$ \\
\hline Mild & 5 & 45.5 & 7 & 63.6 & 3 & 27.3 & 4 & 36.4 \\
Medium & 5 & 45.5 & 3 & 27.3 & 6 & 54.5 & 5 & 45.5 \\
Heavy & 1 & 9.1 & 1 & 9.1 & 2 & 18.2 & 2 & 18.2 \\
\hline
\end{tabular}

Anxiety levels decreased in both groups, but we can see that decreased anxiety levels in the intervention group were more than in the control group. Respondent's severe anxiety cannot be reduced by deep breath relaxation therapy or tahmid therapy. Although there was no decrease in anxiety level, the Zung Anxiety Scale SelfRating Scale score in the two groups equally decreased even though it was not significant.

Anxiety is a psychological response to intellectual assessment of something dangerous (Stuart, 2009). Differences in the level of anxiety of respondents in this study can be associated with differences in anxiety risk factors that are different for each respondent. Differences in age, sex, knowledge, operating experience and socioeconomic level of respondents can affect the level of anxiety of respondents. Anxiety levels are also influenced by individual coping abilities. Individual coping is an individual's ability to cope with situations that can pose threats so that he can overcome uncomfortable feelings such as worry, fear, grieving, and guilt.
TABLE II. ANALYSIS OF DECREASED ANXIETY BEFORE AND AFTER TREATMENT IN THE INTERVENTION AND CONTROL GROUPS

\begin{tabular}{|c|c|c|c|}
\hline Group & Analisa & N & P value \\
\hline Intervention group & $\begin{array}{c}\text { Pre treatmen } \\
\text { Post treatmen }\end{array}$ & 11 & 0.037 \\
\hline Control group & $\begin{array}{c}\text { Pre treatmen } \\
\text { Post treatmen }\end{array}$ & 11 & 0.774 \\
\hline
\end{tabular}

Although there was a decrease in anxiety levels in both groups, the results of the analysis using the Wilcoxon formula showed that there was a significant decrease in anxiety levels in the intervention group $(\mathrm{p}=0.037)$ and there was no significant decrease in the control group $(\mathrm{p}=0.774)$.

This result can be predicted because the level of anxiety in the intervention group decreased more than the control group. This shows that tahmid spiritual therapy can be applied to reduce anxiety levels in pre-SC patients even though patients who experience severe anxiety are less effective to use.

Breathing relaxation therapy is not significant enough to reduce maternal anxiety before SC. Efforts to reduce maternal anxiety before SC can be done by promoting the psychological and spiritual aspects of the patient. A comprehensive nursing approach can improve patient calm and comfort. Humans are not only physiological aspects, but also need psychological, social, cultural and spiritual aspects. Therefore, all nurses must be able and willing to carry out comprehensive nursing care [6].

Sultan Hadlirin's Islamic Hospital, which has a vision to become a leading Islamic hospital that benefits the community, needs to prioritize a spiritual approach as one of its strengths, also because of the Jepara Community, which is predominantly Muslim.

All respondents In this study were Muslim and they all understood the words of tahmid. In the future, efforts can be made to conduct this research in non-Muslim patients while still meeting the ethics of prospective respondents.

TABLE III. ANALYSIS OF DECREASED ANXIETY BETWEEN THE INTERVENTION AND CONTROL GROUPS

\begin{tabular}{|l|l|}
\hline \multirow{2}{*}{ Variable } & Mann_witney \\
\cline { 2 - 2 } & P value \\
\hline $\begin{array}{l}\text { Results of differences in the intervention } \\
\text { group and control group }\end{array}$ & 0.183 \\
\hline
\end{tabular}

Analysis using the mannwhitney formula to test the difference in the reduction of anxiety levels between the intervention group and the control group found no significant difference $(\mathrm{p}=0.183)$.

Statistically, the decrease in anxiety levels between the tahmid spiritual therapy group and deep breathing therapy did not differ significantly. However, spiritual tahmid therapy can still be applied to help reduce anxiety levels in pre-SC patients. The low difference might be due to respondents' previously unknown spiritual intelligence. One's submission to God is influenced by many factors, one of which is spiritual intelligence. Not all people when doing dhikr, heart and mind are really serious to surrender, even though he knows the meaning and meaning of those words. This needs to be considered in future research. 


\section{CONCLUSION}

Spiritual tahmid therapy can significantly reduce pre-SC anxiety levels $(p=0.037)$ while deep breath therapy is not significant $(\mathrm{p}=0.774)$. However, there was no statistically significant decrease in anxiety levels between the two groups $(\mathrm{p}=0.183)$.

\section{RECOMMENDATION}

Nurses can apply spiritual tahmid therapy or other spiritual therapies (adjust to the patient's beliefs) to help reduce anxiety and improve patient comfort. This can not only be applied to pre-sc patients but can also be applied to all conditions.

In subsequent similar studies, researchers can pay attention to the level of spiritual intelligence of respondents. In this study, anxiety is assessed subjectively whose results can be influenced by each person's perception. The next, it can be assessed using cortisol hormone levels and changes in the vital signs of the respondent in order to find more detailed data.

\section{REFERENCES}

[1] Ibrahim, Abdullah MD, et. al. The effect of Benson relaxation method on anxiety in the emergency care. Medicine: May 2019 - Volume 98 - Issue 21 - p e15452. doi: 10.1097/MD.0000000000015452

[2] Karyati, Sri. The Relative Effectiveness of Benson's Relaxation Therapy, Al Quran Murotal Therapy, and Group Communication in the Reduction of Anxiety in Pregnant Women before Labor. International Conference on Public Health.Mey. 2018 ISBN: 978-602-71484-5-1. DOI: https://doi.org/10.26911/theicph.2016.047

[3] Hawari D. Guide to Religious (Islamic) Psychotherapy. Jakarta: FKUI; 2010.

[4] Kamali Z, Tafazoli M, Ebrahimi M, Hosseini M, Saki A, Fayyazi-Bordbar MR, et al. Effect of Spiritual Care Education on Postpartum Stress Disorder in Women with Preeclampsia. Journal of Education and Health Promotion. 2018;7:73.

[5] McBrien B. Emergency Nurses' Provision of Spiritual Care: A Literature Review. British Journal of Nursing (Mark Allen Publishing). 2010;19(12):768-73.

[6] Walpole SC, McMillan D, House A, Cottrell D, Mir G. Interventions for Treating Depression in Muslim Patients: A Systematic Review. Journal of Affective Disorders. 2013;145(1):11-20.

[7] Rafique R, Anjum A, Raheem SS. Efficacy of Surah AlRehman in Managing Depression in Muslim Women. Journal of Religion and Health. 2017.

[8] Moeini M, Taleghani F, Mehrabi T, Musarezaie A., "Effect of a spiritual care program on levels of anxiety in patients with leukemia.," Iran J Nurs Midwifery Res. 2014 Jan;19(1):88-93. PMID: 24554966, 2014 